\title{
Plasma triglyceride concentrations are rapidly reduced following individual bouts of endurance exercise in women
}

\author{
Gregory C. Henderson • Ronald M. Krauss • \\ Jill A. Fattor • Nastaran Faghihnia • \\ Mona Luke-Zeitoun · George A. Brooks
}

Accepted: 15 February 2010/Published online: 9 March 2010

(C) The Author(s) 2010. This article is published with open access at Springerlink.com

\begin{abstract}
It is known that chronic endurance training leads to improvements in the lipoprotein profile, but less is known about changes that occur during postexercise recovery acutely. We analyzed triglyceride (TG), cholesterol classes and apolipoproteins in samples collected before, during and after individual moderate- and hardintensity exercise sessions in men and women that were isoenergetic between intensities. Young healthy men $(n=9)$ and young healthy women $(n=9)$ were studied under three different conditions with diet unchanged between trials: (1) before, during and $3 \mathrm{~h}$ after $90 \mathrm{~min}$ of exercise at $45 \% \mathrm{VO}_{2}$ peak (E45); (2) before, during and $3 \mathrm{~h}$ after $60 \mathrm{~min}$ of exercise at $65 \% \mathrm{VO}_{2}$ peak (E65), and (3) in a time-matched sedentary control trial (C). At baseline, high-density lipoprotein cholesterol (HDL-C) was higher in women than men $(P<0.05)$. In men and in women, total cholesterol (TC), low-density lipoprotein cholesterol (LDL-C), HDL-C, apolipoprotein A-I (apoA-I), apolipoprotein $\mathrm{B}$ (apoB), and LDL peak particle size were unaltered by exercise either during exertion or after $3 \mathrm{~h}$ of recovery. In women, but not in men, average plasma TG was significantly reduced below $\mathrm{C}$ at $3 \mathrm{~h}$ postexercise by approximately $15 \%$ in E45 and $25 \%$ in E65 $(P<0.05)$ with no significant difference between exercise intensities. In summary, plasma TG concentration rapidly declines following exercise in women, but not in men. These results demonstrate an important mechanism by which each
\end{abstract}

Communicated by William Kraemer.

G. C. Henderson - R. M. Krauss - J. A. Fattor - N. Faghihnia ·

M. Luke-Zeitoun · G. A. Brooks ( $\square)$

Exercise Physiology Laboratory, Department of Integrative

Biology, University of California, 5101 Valley Life Sciences

Building, Berkeley, CA 94720-3140, USA

e-mail: gbrooks@berkeley.edu individual exercise session may incrementally reduce the risk for cardiovascular disease (CVD) in women.

Keywords Prior exercise $\cdot$ Post-exercise .

Physical activity $\cdot$ Energy balance $\cdot$ Atherosclerosis

\section{Introduction}

Among the positive effects of leading a physically active lifestyle is the effect of the activity (exercise training) on the lipoprotein profile. Exercise training improves some aspects of plasma lipids, though the precise nature of the effect is variable among studies. Of the many factors that may explain variability, time since the most recent training bout is likely to be very important as the effects of training may wane quickly following cessation of the training program. For example, though reduced plasma triglyceride (TG) concentration in people who regularly exercise may be an important factor in their decreased risk for atherosclerosis and other forms of cardiovascular disease (CVD), the effect may be through the repeated, but transient, impact of each exercise bout on plasma TG, as it was reported that 3 days after cessation of training the favorable training-induced changes were lost (Leon et al. 2000). It may actually be that much of the health benefit of exercise training accrues from exercisers being in a perpetual state of postexercise recovery. Thus, studies of postexercise recovery following individual bouts of exercise could indicate important health benefits of regular exercise.

Though studies have not yet revealed differences between men and women or the effects of exercise intensity, there are reports of acute effects of exercise on the lipoprotein profile during recovery. To assess acute changes in the lipoprotein profile following exercise 
sessions, it is important to control for diurnal variations and for drift of nutritional state between meals by conducting time-of-day-matched sedentary control trials on separate occasions. Thus, as performed in the studies discussed below, changes that occur during postexercise recovery can be compared to changes that may occur on sedentary occasions. There appear to be no significant changes in total cholesterol (TC) or low-density lipoprotein cholesterol (LDL-C) in either sex during the hours following a single exercise session (Gill et al. 2003; Gordon et al. 1996; Lee et al. 1991), but results for TG and HDL-C are somewhat more promising. In women, following an acute exercise bout, it was reported that plasma TG concentration declined within 90 min after exercise (Lee et al. 1991) and the effect was sustained until the following day (Gill et al. 2003; Lee et al. 1991), though others did not find TG to be depressed on the day after exercise (Magkos et al. 2009). In men, results have been variable showing no effect (Gordon et al. 1996; Magkos et al. 2007) or depressed plasma TG during recovery when exercise volume was quite high (Magkos et al. 2006), but it was unknown if impacts of exercise would have been clearer if plasma samples had been drawn closer in time to the exercise session rather than so far out into the recovery period. That is to say, the effects of a single bout of exercise might primarily act during the few hours after exercise rather than being delayed until the day following exercise. Studies that directly compare men with women during the hours immediately following exercise are still needed. Additionally, exercise bouts can lead to subsequently elevated concentrations of high-density lipoprotein cholesterol (HDL-C) in women (Lee et al. 1991) and men (Gordon et al. 1996), though little is known about the effects of exercise intensities, energy expenditures or effects of gender when controlling for changes that may occur during the course of a sedentary day.

Compared to men of similar age, premenopausal women have been shown to have a more favorable lipoprotein profile (Després et al. 1999; Freedman et al. 1990; Johnson et al. 2004; Leon et al. 2000; St-Amand et al. 1995), of which the most substantial differences seem to be having lower plasma TG and higher plasma HDL-C. Additionally, women may have lower postprandial lipemia because of more rapid clearance of meal fatty acids away from chylomicrons to peripheral storage sites (Knuth and Horowitz 2006). Thus, it appears that there are some important gender differences with regard to lipoprotein metabolism and CVD risk. However, how these gender differences interact with changes in lipemia following physical activity is not yet known and, furthermore, the effects of the intensity of exercise have not yet been determined. Therefore, we studied the lipoprotein profile in young men and women during and $3 \mathrm{~h}$ after exercise sessions of two different relative intensities that were matched for energy expenditure within each sex. Importantly, because the effects of exercise would be overlaid on the effects of the time of day and time course of meal absorption, we compared the results to a sedentary condition in which diet was identical. We conjectured that the effects of chronic exercise training to increase HDL-C (Després et al. 1990; Katzmarzyk et al. 2001; Kiens et al. 1980; Kraus et al. 2002; Leon et al. 2000; Slentz et al. 2007; Thompson et al. 1988; Williams et al. 2005) and reduce TG (Kiens et al. 1980; Kraus et al. 2002; Leon et al. 2000; Thompson et al. 1988) are an accumulation of changes that occur following each individual exercise bout and largely reflect the impact of the most recent session. Furthermore, though far more investigation is needed to understand the importance of exercise training intensity, higher-intensity exercise is believed to lead to some additional healthy benefits beyond that of lower-intensity exercise (Institutes of Medicine 2002). Thus, we hypothesized that an exercise bout would acutely raise HDL-C and lower plasma TG in an intensitydependent manner in both sexes. The results revealed an important sex-based difference for the impact of physical activity on plasma lipids and revealed a potential mechanism by which a physically active lifestyle reduced CVD risk in young women.

\section{Methods}

\section{Study participants}

Moderately active, non-smoking, weight-stable volunteers were recruited from the University of California, Berkeley campus and surrounding community by posted notice and e-mail. Initially, 10 men and 10 women were recruited to participate in the study. Potential study participants underwent subsequent screening tests for being diseasefree as determined by physical examination and health history questionnaire. They were not taking medications known to affect metabolism, had a body mass index (BMI) of less than 28, were neither sedentary individuals (abstinence from any regular exercise) nor elite athletes (intercollegiate or professional athletes) and had normal lung function as determined by 1-s forced expiratory volume of greater than or equal to $70 \%$ of vital capacity. Female study participants reported regular menstrual cycles (24-32 days) and were not taking oral contraceptives or other forms of exogenous ovarian hormones. We sought to study women in the early follicular phase of the menstrual cycle to standardize conditions between trials. Therefore, female subjects were studied between days 3 and 8 of their menstrual cycles, and the cycle phase was subsequently confirmed if estradiol was less than $50 \mathrm{pg} / \mathrm{mL}$ and 
progesterone was less than $1 \mathrm{ng} / \mathrm{mL}$ in serum collected the morning of each study occasion. In two women, serum estradiol concentrations were greater than $50 \mathrm{pg} / \mathrm{mL}$ in one of the trials. For one woman, this was on an exercise day and that trial was excluded. For the other woman, the elevation of estradiol occurred on the control day and so all three of her trials were excluded. Additionally, we were unable to attain data in every trial for the men. Therefore, participants per trial ranged from seven to nine for men and eight to nine for women. In Table 1, we report the characteristics of the study participants. Habitual exercise activity of approximately 6-7 h/week of moderate exertion (more intense than walking and less intense than competitive sporting competition) was reported by both the men and women. Procedures and risks were thoroughly explained to the study participants, and their written, informed consent was obtained. The University of California, Berkeley Committee for the Protection of Human Subjects approved the study protocol (CPHS no. 2004-6103).

\section{Screening tests}

Before beginning the study, participants underwent two progressive exercise tests to assess peak oxygen consumption $\left(\dot{V} \mathrm{O}_{2}\right.$ peak $)$ and body composition was assessed by skinfold measurement (Jackson and Pollock 1978; Jackson et al. 1980). In previous investigations, we found the skinfold and hydrostatic weighing methods to provide similar results on the study population of interest (Friedlander et al. 1998, 1999). As changes over time in physical fitness and body fat content could alter lipoprotein profiles, $\dot{V} \mathrm{O}_{2}$ peak and body composition assessments were again

Table 1 Characteristics of study participants

\begin{tabular}{lrr}
\hline & \multicolumn{1}{c}{ Men } & \multicolumn{1}{c}{ Women } \\
\hline Age (year) & $25.2 \pm 1.7$ & $25.1 \pm 2.0$ \\
Height $(\mathrm{cm})$ & $176.5 \pm 2.2^{\dagger}$ & $160.0 \pm 1.6$ \\
Weight $(\mathrm{kg})$ & $71.9 \pm 3.7^{\dagger}$ & $57.8 \pm 1.7$ \\
BMI $\left(\mathrm{kg} / \mathrm{m}^{2}\right)$ & $23.0 \pm 0.7$ & $22.6 \pm 0.7$ \\
Body fat $(\%)$ & $10.9 \pm 1.6^{\dagger}$ & $22.5 \pm 0.9$ \\
FFM $(\mathrm{kg})$ & $64.1 \pm 3.5^{\dagger}$ & $44.5 \pm 1.0$ \\
Fat mass $(\mathrm{kg})$ & $7.9 \pm 1.2^{\dagger}$ & $13.4 \pm 0.8$ \\
$\dot{V} \mathrm{O}_{2}$ peak $(\mathrm{L} / \mathrm{min})$ & $4.2 \pm 0.3^{\dagger}$ & $2.7 \pm 0.1$ \\
$\dot{V} \mathrm{O}_{2}$ peak $(\mathrm{mL} / \mathrm{kg} / \mathrm{min})$ & $57.6 \pm 2.2^{\dagger}$ & $46.7 \pm 2.5$ \\
$\dot{V} \mathrm{O}_{2}$ peak $(\mathrm{mL} / \mathrm{kg} \mathrm{FFM} / \mathrm{min})$ & $64.5 \pm 1.9$ & $60.6 \pm 3.0$ \\
Exercise $(\mathrm{h} / \mathrm{week})$ & $7.0 \pm 1.0$ & $6.2 \pm 0.5$ \\
\hline
\end{tabular}

Values are means \pm SE. Men, $n=7$; women, $n=8 . \dot{V} \mathrm{O}_{2}$ peak, peak $\mathrm{O}_{2}$ consumption, $B M I$ body mass index, $F F M$ fat-free mass. Statistical analysis by unpaired $t$ test

Significantly different between men and women, ${ }^{\dagger} P<0.05$ carried out on completion of the study to confirm that changes had not occurred during the time in which participants were enrolled in the study. $\dot{V} \mathrm{O}_{2}$ peak and body composition did not vary significantly between assessments. Exercise was performed on a leg-cycle ergometer (Monark Ergometric 839E, Vansbro, Sweden). Additionally, as changes in dietary composition over time in study participants could alter results, dietary energy and macronutrient intake were monitored at the beginning, middle and end of the study by separate 3-day diet records; analysis was performed with Diet Analysis Plus 6.1 software (ESHA Research, Salem, OR, USA). Diets did not vary significantly between the three separate assessments and, therefore, average values are reported.

\section{Experimental design}

With at least 1 week between trials for men and 1 month between trials for women, participants were studied under each of the three conditions, each on separate occasions, assigned in a random order. Men and women were studied (1) before, during, and $3 \mathrm{~h}$ after $\sim 90 \mathrm{~min}$ of exercise at $45 \% \dot{V} \mathrm{O}_{2}$ peak (E45), (2) before, during and $3 \mathrm{~h}$ after $\sim 60 \mathrm{~min}$ of exercise at $65 \% \quad \dot{\mathrm{V}} \mathrm{O}_{2}$ peak (E65), and (3) during a time-matched resting control trial (C). After catheterization, study participants lay semi supine quietly reading or watching movies. After exercise, study participants dismounted the ergometer and sat on a chair where they remained for $30 \mathrm{~min}$ and were then transferred to an examination table where they remained semi supine for the remaining $2.5 \mathrm{~h}$ of postexercise recovery. Water was consumed by study participants ad libitum, but they consumed no food during recovery. Participants were transported in a wheelchair for trips to the toilet. Duration of the first randomly assigned exercise trial, either E45 or E65, was set at 90 or $60 \mathrm{~min}$, respectively. The appropriate duration for the subsequent exercise trial in the remaining exercise condition was predicted with the goal of matching exercise energy expenditure (EEE) between exercise bouts using oxygen consumption $\left(\dot{V} \mathrm{O}_{2}\right)$ and respiratory exchange ratio (RER) from the $\dot{V} \mathrm{O}_{2}$ peak assessments.

\section{Experimental protocol}

For the day prior to studies, participants were instructed to consume a standardized diet and water ad libitum, and to abstain from structured physical exercise sessions, but to continue typical activities of daily living. On the day preceding the studies, participants were fed for a physical activity level (PAL) of 1.5 according to the current dietary reference intake guidelines of the Institutes of Medicine for estimated energy requirement (EER) (Institutes of Medicine 2002). These standardized diets were individualized 
for each study participant (men $2,762 \pm 68 \mathrm{kcal} / \mathrm{day}$, women $2,101 \pm 36 \mathrm{kcal} /$ day) and macronutrient composition was made similar between individuals for carbohydrate (men $50.2 \pm 0.3 \%$, women $50.2 \pm 0.2 \%$ ), fat (men $31.9 \pm 0.3 \%$, women $32.3 \pm 0.4 \%$ ) and protein (men $17.9 \pm 0.5 \%$, women $17.6 \pm 0.2 \%$ ). On the study days, participants arrived at the laboratory at 7:00 a.m. after overnight fasting and ate a standardized breakfast (men $450 \mathrm{kcal}, 67 \%$ carbohydrate, $22 \%$ fat, $11 \%$ protein; women $345 \mathrm{kcal}, 65 \%$ carbohydrate, $26 \%$ fat, $9 \%$ protein) that represented approximately $16 \%$ of EER in both men and women. We chose to feed our study participants a standardized small breakfast $3 \mathrm{~h}$ before exercise to mimic typical nonlaboratory conditions, and following breakfast no more food was consumed until after the last blood sample was drawn. On the morning of the studies, a catheter was placed in a hand vein to collect arterialized blood using the heated hand vein technique (Horning et al. 1998), and pulmonary gas exchange was determined for assessment of metabolic rate and substrate oxidation, which we reported previously (Henderson et al. 2007a). At each sampling time point, heart rate was recorded from an electrocardiograph (Quinton Q750, Seattle, WA, USA).

\section{Blood sampling}

Arterialized venous blood samples were drawn immediately before exercise, in the last moments of exercise bouts $\left(\sim 90 \mathrm{~min}\right.$ at $45 \% \quad \mathrm{VO}_{2}$ peak and $\sim 60 \mathrm{~min}$ at $65 \%$ $\mathrm{VO}_{2}$ peak), and then $3 \mathrm{~h}$ after exercise during recovery. During the $\mathrm{C}$ trial, blood samples were drawn at the time point corresponding to pre-exercise ( $3 \mathrm{~h}$ after breakfast), $75 \mathrm{~min}$ later, and then $3 \mathrm{~h}$ later to correspond to approximate times of day that samples were taken in E45 and E65. Blood was collected into tubes containing EDTA (0.15\%), enzyme inhibitors (D-phenylalanyl-L-prolyl-L-arginyl- $\mathrm{CHCl}_{2}$, $1 \mu \mathrm{M}$; aprotinin, $50 \mathrm{KU} / \mathrm{mL}$ ), antibiotics (gentamicin sulfate, $50 \mu \mathrm{g} / \mathrm{mL}$; chloramphenicol sodium succinate, $0.05 \mathrm{mg} / \mathrm{mL}$ ), and a bacteriocide (sodium azide, $0.01 \%$ $\mathrm{wt} / \mathrm{vol})$. Blood was centrifuged at $3,000 \times g$ for $20 \mathrm{~min}$ and the plasma stored at $-80^{\circ} \mathrm{C}$ with the tubes' headspaces filled with nitrogen gas. Hematocrit measurements were performed on arterialized venous blood using a circular microcapillary tube reader.

\section{Sample analyses}

Plasma was analyzed for concentrations of TC (Allain et al. 1974), TG (Nagele et al. 1984) and HDL-C measured directly after precipitation of apoB containing lipoproteins in plasma (Warnick et al. 1985). LDL-C was calculated from the formula of Friedewald et al. (Friedewald et al. 1972). Lipid assays were enzymatic end-point measurements utilizing enzyme reagent kits and a CibaCorning Express 550 automated analyzer (Ciba-Corning Diagnostics, Oberlin, OH, USA). The measurements were standardized through the CDC-NHLBI Lipid Standardization Program. Measurement of LDL peak particle size was performed on whole plasma with the use of nondenaturing $2-14 \%$ polyacrylamide gradient gel electrophoresis and standardized conditions (Nichols et al. 1986). Following electrophoresis, lipoproteins were lipid stained with Sudan Black, and the protein calibration standards were stained with Coomassie R-250. Gels were analyzed using computer-automated densitometry, and calculations of peak particle sizes were based on the migration of reference standards of known particle size. An immunoturbidimetric assay (Rifai and King 1986; Smith et al. 1987) was used to measure apoA-I and apoB. Reagents, standards and reference plasma controls, with and without elevated lipids, were included in the immunoturbidimetric assay reagent kit (Bacton Assay Systems, San Marcos, CA, USA). Measurements were performed using the Express Plus 550 analyzer according to kit instructions. Calibrators and reference controls were assigned concentration values with the use of International Federation of Clinical Chemistry standard reference materials SP1 for apoA-I and SP3-07 for apoB. In-house controls were measured in each group of 20 unknowns, as well. For each assay, coefficients of variation were less than $10 \%$, and all samples were analyzed in duplicate.

\section{Calculations}

EEE was assessed by pulmonary gas exchange (Frayn 1983) and was calculated for each exercise intensity in each individual by subtracting the background resting energy expenditure rate in the $\mathrm{C}$ trial from the energy expenditure of the exercise sessions. Baseline lipoprotein concentration values are reported as those measured in plasma and the subsequent two samples in a trial were corrected for estimated changes in plasma volume from baseline using hematocrit (van Beaumont 1973).

\section{Statistical analyses}

Data are presented as mean \pm standard error. Subject characteristics and baseline (pre-exercise) lipoprotein values were compared between genders by unpaired $t$ test. Additional specific unpaired $t$ tests comparing men with women were performed for values during exercise of a given intensity. Also, with unpaired $t$ tests, we compared between sexes the relative change from baseline during exercise trials to that in $\mathrm{C}$ trials when either sex showed a significant difference from $\mathrm{C}$ after exercise. Results for percentage change from pre-exercise values were analyzed 
within sexes by repeated measures analysis of variance (trial $\times$ time) with post hoc analyses by Fisher's protected least significant difference test. Statistical analyses were performed using JMP 7.0 software (SAS, Inc., Cary, NC, USA), and the statistical significance was set at $\alpha=0.05$.

\section{Results}

Diet records

As expected, reported habitual dietary energy intake was significantly higher in men than women (men 2,435 \pm $112 \mathrm{kcal} /$ day, women $1,966 \pm 96 \mathrm{kcal} /$ day, $P<0.05$ ). Habitual dietary macronutrient composition was not significantly different between sexes for carbohydrate (men $54.1 \pm 2.0 \%$, women $54.0 \pm 1.8 \%$ ), lipid (men $28.9 \pm$ $2.0 \%$, women $29.4 \pm 1.3 \%$ ) and protein (men $17.0 \pm 0.6 \%$, women $16.6 \pm 0.8 \%)$.

\section{Characteristics of exercise bouts}

EEE was significantly greater in men than women $(P<0.05)$. The durations of E45 (men $88.8 \pm 0.5 \mathrm{~min}$, women $90.4 \pm 0.9 \mathrm{~min}$ ) and E65 (men $60.4 \pm 0.2 \mathrm{~min}$, women $61.2 \pm 0.6 \mathrm{~min}$ ) were such that energy expenditures would be similar for the two intensities for both men and women. EEE was matched between exercise trials in that there were no significant differences between trials for men (E45 $693 \pm 55 \mathrm{kcal}, \mathrm{E} 65698 \pm 57 \mathrm{kcal})$ and women (E45 $427 \pm 24 \mathrm{kcal}, \mathrm{E} 65439 \pm 24 \mathrm{kcal})$. As the physical fitness level $\left(\dot{V} \mathrm{O}_{2}\right.$ peak per FFM) was similar between men and women, $\dot{V} \mathrm{O}_{2}$ was not significantly different between sexes during exercise when expressed per FFM in either $\mathrm{E} 45$ or E65, and relative exercise intensities were also similar for the sexes in $\mathrm{E} 45$ (men $46.5 \pm 0.5 \% \dot{\mathrm{V}} \mathrm{O}_{2}$ peak, women $46.2 \pm 1.2 \% \quad \dot{V} \mathrm{O}_{2}$ peak) and $\mathrm{E} 65$ (men $64.9 \pm$ $1.5 \% \dot{V} \mathrm{O}_{2}$ peak, women $65.2 \pm 0.6 \% \dot{V} \mathrm{O}_{2}$ peak). The heart rates elicited during exercise were similar between men and women for E45 (men $129 \pm 1$ beats/min, women $122 \pm 5$ beats $/ \mathrm{min}$ ) and E65 (men $156 \pm 3$ beats $/ \mathrm{min}$, women $152 \pm 5$ beats/min).

\section{Lipoprotein profile}

The baseline (pre-exercise) lipoprotein profiles for men and women are reported in Table 2. As conditions were similar between the three trials (C, E45, E65) for the pre-exercise time point, we report averages of the three occasions. Baseline HDL-C was significantly higher in women than men $(P<0.05)$. Baseline TG was not significantly different between men and women $(P=0.12)$, nor were TC
Table 2 Pre-exercise lipoprotein profile

\begin{tabular}{lrr}
\hline & \multicolumn{1}{c}{ Men } & \multicolumn{1}{c}{ Women } \\
\hline Triglyceride $(\mathrm{mg} / \mathrm{dL})$ & $88.4 \pm 9.2$ & $71.3 \pm 4.9$ \\
Total cholesterol $(\mathrm{mg} / \mathrm{dL})$ & $135.3 \pm 7.5$ & $143.4 \pm 9.2$ \\
LDL cholesterol $(\mathrm{mg} / \mathrm{dL})$ & $69.6 \pm 7.1$ & $66.0 \pm 8.9$ \\
HDL cholesterol $(\mathrm{mg} / \mathrm{dL})$ & $48.2 \pm 2.8^{\dagger}$ & $63.2 \pm 4.0$ \\
Apoprotein A-I $(\mu \mathrm{g} / \mathrm{mL})$ & $1,221 \pm 101$ & $1,460 \pm 95$ \\
Apoprotein B $(\mu \mathrm{g} / \mathrm{mL})$ & $579 \pm 50$ & $528 \pm 50$ \\
LDL peak particle size $(\AA)$ & $267.8 \pm 1.6$ & $272.1 \pm 1.5$ \\
\hline
\end{tabular}

Values are means \pm SE. Men, $n=9$; women, $n=9$. $L D L$ lowdensity lipoprotein, $H D L$ high-density lipoprotein. Plasma was collected immediately preceding exercise and at the corresponding time of day in the control trial. Values are averaged between three occasions. Statistical analysis by unpaired $t$ test

Significantly different between men and women, ${ }^{\dagger} P<0.05$

$(P=0.51)$, LDL-C $(P=0.75)$, apoA-1 $(P=0.10)$, apoB $(P=0.48)$ or LDL peak particle size $(P=0.08)$. During exercise of either intensity, HDL-C and ApoA-I were significantly higher in women than men $(P<0.05)$, which primarily reflected the baseline values, as concentrations in either sex had not changed substantially from baseline.

The relative changes from pre-exercise for cholesterol subfractions and apolipoproteins are reported in Table 3 and for plasma TG in Fig. 1. In men, there was a main effect of time for TG to decrease across the day $(P<0.05)$, and for LDL-C $(P<0.05)$ and HDL-C $(P<0.05)$ to increase. However, in men there were no main effects of trial and no trial $\times$ time interactions. In women, there was a significant trial $\times$ time interaction for relative change of TG from pre-exercise values, and post hoc testing revealed that E45 and E65 were significantly lower than C during postexercise recovery $(P<0.05)$. In women, on subtracting the approximate drift of $1 \%$ from pre-exercise to postexercise time points in $\mathrm{C}$, in $\mathrm{E} 45$ the net decline of plasma TG below $\mathrm{C}$ was $15 \%$ and in E65 was $25 \%$ below C. In men, there was no significant postexercise decline of TG versus the $\mathrm{C}$ trial, and across the day in both $\mathrm{E} 45$ and $\mathrm{E} 65$, the percentage of change versus that in $\mathrm{C}$ was significantly greater for women than men $(P<0.05)$. However, though this substantial gender difference became apparent during recovery, during the exercise bouts there were not yet any significant differences for TG changes between men and women. In women, there was a main effect of time for TC to increase $(P<0.05)$, and as in men, there were main effects for LDL-C $(P<0.05)$ and HDL-C $(P<0.05)$ to increase slightly during the day. Apolipoproteins and LDL particle size changed neither during a sedentary day nor during exercise or recovery. 
Table 3 Relative lipoprotein concentration changes (\%) during exercise and recovery

\begin{tabular}{lrrrrrr}
\hline \multicolumn{1}{c}{ TC } & LDL-C $^{\#}$ & HDL-C & ApoA-I & ApoB & LDL size \\
\hline Men & & & & & \\
Exercise & & & & & \\
C & $0 \pm 2$ & $2 \pm 3$ & $0 \pm 2$ & $-2 \pm 5$ & $-2 \pm 4$ & $0 \pm 0$ \\
E45 & $0 \pm 1$ & $-2 \pm 1$ & $0 \pm 1$ & $2 \pm 3$ & $-5 \pm 4$ & $0 \pm 0$ \\
E65 & $-1 \pm 2$ & $-1 \pm 3$ & $-5 \pm 1$ & $-9 \pm 5$ & $-6 \pm 7$ & $0 \pm 0$ \\
Recovery & & & & & \\
C & $0 \pm 2$ & $5 \pm 3$ & $0 \pm 3$ & $2 \pm 6$ & $3 \pm 7$ & $0 \pm 0$ \\
E45 & $2 \pm 2$ & $3 \pm 2$ & $4 \pm 1$ & $-3 \pm 3$ & $5 \pm 5$ & $0 \pm 0$ \\
E65 & $1 \pm 2$ & $7 \pm 3$ & $2 \pm 2$ & $1 \pm 6$ & $-7 \pm 7$ & $0 \pm 0$ \\
Women & & & & & & \\
Exercise & & & & & & \\
C & $0 \pm 2$ & $1 \pm 2$ & $-1 \pm 2$ & $-2 \pm 7$ & $3 \pm 4$ & $0 \pm 0$ \\
E45 & $0 \pm 1$ & $0 \pm 3$ & $-2 \pm 1$ & $0 \pm 4$ & $12 \pm 7$ & $-1 \pm 0$ \\
E65 & $-3 \pm 1$ & $-3 \pm 2$ & $-4 \pm 1$ & $-5 \pm 3$ & $-8 \pm 4$ & $0 \pm 0$ \\
Recovery & & & & & \\
C & $5 \pm 2$ & $9 \pm 2$ & $3 \pm 2$ & $0 \pm 5$ & $7 \pm 5$ & $0 \pm 0$ \\
E45 & $1 \pm 2$ & $9 \pm 5$ & $1 \pm 1$ & $0 \pm 6$ & $7 \pm 5$ & $0 \pm 1$ \\
E65 & $1 \pm 1$ & $8 \pm 3$ & $2 \pm 2$ & $0 \pm 4$ & $-3 \pm 5$ & $0 \pm 0$ \\
\hline
\end{tabular}

Values are means \pm SE for percentage change from baseline. Men, $n=7-9$; women, $n=8-9$

$C$ control trial, $E 4545 \% \dot{V} \mathrm{O}_{2}$ peak trial, $E 6565 \% \dot{V} \mathrm{O}_{2}$ peak trial, $T G$ triglyceride, $T C$ total cholesterol, $L D L-C$ low-density lipoprotein cholesterol, $H D L-C$ high-density lipoprotein cholesterol, Apo apolipoprotein, $L D L$ size LDL peak particle size expressed as diameter

Statistical analysis was performed with ANOVA. Main effect of time in both sexes, ${ }^{\#} P<0.05$. No main effects of trial and no trial $\times$ time interactions were observed

\section{Discussion}

Here, we report that in healthy, young and moderately fit individuals, a single session of exercise does not change plasma apolipoproteins, TC, LDL-C, HDL-C or LDL particle size. However, of importance, we report the novel finding that plasma TG declines substantially within $3 \mathrm{~h}$ of exercise in women, but is not different from resting in men when a time-of-day comparison is made. It is recommended that exercise be performed every day (Institutes of Medicine 2002), and so individuals following this recommendation will spend a significant portion of their lives in a state of postexercise recovery. Hence, any important aspects of metabolism or of the lipoprotein profile that change during this time period (e.g., TG in women) could vastly affect an active person's risk factor profile.

Our present results indicate that a single exercise bout of reasonable volume can lower plasma TG in women and that the effect may primarily occur within the day of the exercise bout. On the contrary, it appears that any potential
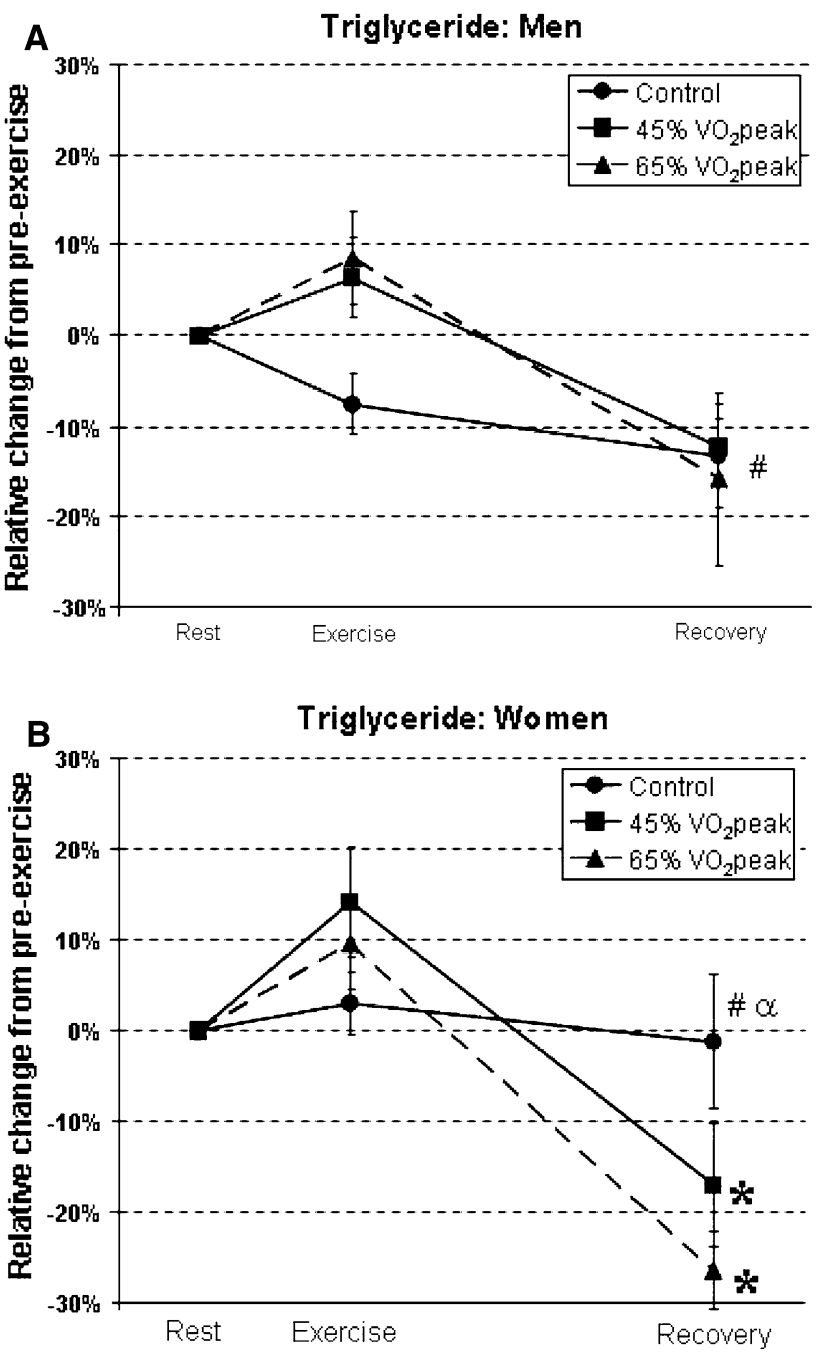

Fig. 1 Plasma triglyceride over the course of a sedentary day and on days with exercise bouts in men (a) and women (b). Values are means \pm SE. Men, $n=7-9$; women, $n=8-9$. Statistical analysis was performed by ANOVA with Fischer's LSD post hoc test. Main effect of time, ${ }^{\#} P<0.05$. No main effects of trial were observed. Time $\times$ trial interaction, ${ }^{\alpha} P<0.05$. Significantly different from corresponding Con by Fischer's LSD post hoc test, $* P<0.05$

effects of exercise on TG in men or on HDL-C in either gender may require exercise sessions on sequential days, longer exercise duration or more than $3 \mathrm{~h}$ of recovery to become detectable. We have conducted studies of postexercise recovery in men and women for $3 \mathrm{~h}$ following exercise (Henderson et al. 2007a, b, 2008), as well as on the day after exercise (Henderson et al. 2007a). In these studies (Henderson et al. 2007a, b, 2008), we showed that whole body glycerol flux (lipolysis), plasma free fatty acid (FFA) flux and plasma FFA concentration were elevated to a greater extent in men than women during $3 \mathrm{~h}$ of postexercise recovery (Henderson et al. 2007a). The present results for postexercise plasma lipids show that changes in plasma TG are dissociated from changes in postexercise 
lipolysis and fatty acid metabolism, in that the sex with a lesser elevation of systemic FFA mobilization (women) actually showed a greater postexercise decline of plasma TG. In addition to our study on whole body glycerol and FFA kinetics, others have studied FFA and plasma TG kinetics in men (Magkos et al. 2006, 2007) and women (Magkos et al. 2009) on the day following exercise. They showed that on the next day following exercise of $2 \mathrm{~h}$ at $60 \% \quad \dot{V} \mathrm{O}_{2}$ peak, men display elevated FFA flux and depressed plasma TG concentrations (Magkos et al. 2006), but that the effect on plasma TG was not attained if the exercise duration was only $1 \mathrm{~h}$ (Magkos et al. 2007). These results for elevated postexercise FFA flux the day after exercise mirror our finding for FFA flux during hours immediately following exercise (Henderson et al. 2007a) and the results also suggest that the threshold of exercise volume for affecting plasma TG in men may be such that a quite large exercise volume is needed. In women, on the day following $1 \mathrm{~h}$ of exercise at $60 \% \dot{V} \mathrm{O}_{2}$ peak, it was reported that neither FFA flux nor plasma TG concentrations were affected (Magkos et al. 2009). However, studying a different portion of the recovery period, we report here that plasma TG is significantly depressed $3 \mathrm{~h}$ after exercise in women, and so the timing of the measurements appears to be of considerable importance.

Compared with men, women display a greater response of the lipoprotein profile during recovery from exercise regardless of whether the bout was of a moderate or hard intensity. Thus, we presently describe a gender-specific benefit of individual bouts of exercise. If the absolute EEE were the major determinant of plasma TG changes during recovery, then one would expect a greater decline in men as absolute EEE was higher in men (because men have higher FFM), and so clearly EEE is not the major determinant of the TG response. Previously, the work of others showed us that in women and men with similar exercise intensities and durations, plasma TG may be similarly unaltered on the day following exercise bouts of a 1-h duration (Magkos et al. 2007, 2009). However, in women, even with a reasonable exercise volume (duration of $45 \mathrm{~min}$ ), it was shown that TG can decline within even $1.5 \mathrm{~h}$ of exercise cessation (Lee et al. 1991), but it was not yet known if TG could decline soon after exercise in men as well. On the whole, it appears possible that the important effects of exercise on plasma TG primarily occur within the day of the exercise bout and especially in women.

To consider factors that may be involved in the sexbased differences in postexercise TG metabolism, lipoprotein lipase (LPL) ought to be considered, as it is an important enzyme in muscle and adipose tissue capillary beds that promotes clearance of plasma TG and is known to be responsive to exercise and to changes in energy balance. At rest, compared to men, women have slightly higher total body LPL activity (Després et al. 1999) and substantially higher adipose tissue LPL activity (St-Amand et al. 1995). This could explain the tendency for women to have lower plasma $\mathrm{TG}$ in the $\mathrm{C}$ trial in this study, but a differential response between the sexes for LPL to prior exercise would be more helpful in explaining our results for postexercise plasma TG. In a previous study, in which men and women were grouped together into a single subject pool, it was shown that muscle LPL protein content was not yet elevated at $0.2 \mathrm{~h}$ after exercise, but was subsequently elevated substantially in a muscle sample taken $4 \mathrm{~h}$ after exercise (Seip et al. 1997). So, it is fairly probable that during the $3 \mathrm{~h}$ of postexercise recovery in our study that muscle LPL activity may have been elevated at some point. However, it is unknown if there is a sex difference in LPL activity during the hours after exercise, and addressing this issue may be an important direction for future investigations.

With regard to postexercise hypotriglyceridemia in women, another possible explanation could be that, rather than plasma TG clearance being elevated in women during recovery, plasma TG synthesis might have been depressed, leading to declining plasma TG abundance. Indeed, it is known that elevated FFA concentrations in plasma can lead to higher plasma TG via an increased TG synthesis rate (Lewis et al. 1995). Thus, as we previously reported in these same study participants that plasma FFA concentrations in recovery were elevated to a much lesser extent in women than men (Henderson et al. 2007a), this may have led to a slower VLDL TG synthesis rate in the women and hence to a declining plasma TG concentration. Though elevated plasma FFA in men in recovery may promote lipid oxidation, it may also promote plasma TG synthesis and therefore prevent postexercise hypotriglyceridemia. Thus, the reason why women can achieve postexercise hypotriglyceridemia could be related to their maintenance of whole body lipolysis at basal levels during this period.

Though the pre-exercise breakfast in our study was small and low in fat, it is possible that our findings were based at least partly in differences of the effect of exercise on chylomicron metabolism between the sexes, as our analysis of plasma TG did not differentiate between exogenous and endogenous sources. After consumption of a large high-fat meal, in comparison to men, women were previously shown to have lower postprandial lipemia because of more rapid clearance of meal fatty acids away from chylomicrons (Knuth and Horowitz 2006). With regard to clinical relevance, it is known that both elevated fasting and postprandial plasma TG are associated with CVD risk (Austin et al. 1998; Bansal et al. 2007; Stampfer et al. 1996). Thus, whether the postexercise depression of plasma TG in women represents lowered endogenous plasma TG or lowered chylomicrons, either way such a drop in total plasma $\mathrm{TG}$ can be reasoned to have a 
beneficial impact. Though a standard practice may be to measure lipoproteins in the overnight-fasted state, we fed our subjects breakfast to mimic nonlaboratory conditions and so we believe that our findings relate to the practical importance of exercise for altering metabolism of plasma lipids throughout a day of life. It is known that physically active individuals experience less risk of CVD (Institutes of Medicine 2002), and we propose that an important mechanism by which this occurs in women is by transient declines of plasma TG during postexercise recovery. In men, any effects via plasma lipids may occur later in recovery or indirectly via training-induced loss of body fat.

Our results indicate that when women have exercised earlier in the day, their plasma TG will be substantially lower than it would be on a sedentary occasion. Compared to the effects of chronic training on plasma TG (Kiens et al. 1980; Kraus et al. 2002; Leon et al. 2000; Thompson et al. 1988), which are not sustained well and are of limited magnitude (Leon et al. 2000), the acute effect of exercise on plasma TG in women (Fig. 1) is appreciable. In comparison to their time-matched sedentary control trials, this response of plasma TG was not observed in men in the present study. In men, plasma TG declined somewhat throughout the day in the $\mathrm{C}$ trial such that postexercise declines were not different from declines that would occur on a sedentary day. The decline of TG in the $\mathrm{C}$ trial in men may have been related to their lipemic response to the breakfast meal, or may represent some other gender difference in diurnal TG variation. Nonetheless, as C trials in men and women were qualitatively different, it was clearly essential to compare postexercise data to a control trial to determine the effects of exercise per se. Our present results regarding acute effects of prior exercise on plasma TG add to the growing body of knowledge describing differences between men and women for the acute and chronic responses to endurance exercise. Such gender differences, in addition to that which we report here, include that women, compared to men, derive a higher percentage of energy from lipid and less from carbohydrate during endurance exercise (Carter et al. 2001; Devries et al. 2006, 2007; Friedlander et al. 1998, 1999; Henderson et al. 2007a, b; Horton et al. 1998; Phillips et al. 1993; Tarnopolsky et al. 1990, 2007) and thus appear better equipped to utilize lipids as fuel. But, from previous work, it is also known that in response to chronic endurance training, men lose more body fat than do women (Ballor and Keesey 1991; Donnelly and Smith 2005), which may be related to higher increments of postexercise lipid mobilization in men than women (Henderson et al. 2007a). Thus, it continually becomes increasingly more evident that the metabolic responses to exercise are different between men and women.
In conclusion, exercise impacts metabolism in qualitatively different manners between the sexes. In the hours following exercise, the lipoprotein profile is unaltered in men, but is favorably changed in women. Our present results indicate that exercise acutely leads to a decline of plasma TG in women even within $3 \mathrm{~h}$ of the exercise bout. Furthermore, when energy expenditure is matched between exercise intensities, the response is similar between two different exercise sessions. The results of this study indicate that women will spend a significant portion of their lives in a hypotriglyceridemic state if they exercise regularly because of rapid declines of plasma TG during the hours following each exercise session. These results add to the complexity and elaborate nature of our growing knowledge of gender differences in the physiological responses to exercise.

Acknowledgments We thank the study participants for their time and compliance with the protocol. We also thank Tamara Mau, Matthew Johnson, Martina Patella, Betty Liang and Rowan Sill for providing laboratory support. This work was supported by the National Institute of Health grant AR 42906 and by gifts from the Brian and Jennifer Maxwell Foundation and CytoSport, Inc. The experiments comply with the current laws of the USA.

Conflict of interest Statement The authors declare that they have no conflict of interest.

Open Access This article is distributed under the terms of the Creative Commons Attribution Noncommercial License which permits any noncommercial use, distribution, and reproduction in any medium, provided the original author(s) and source are credited.

\section{References}

Allain CC, Poon LS, Chan CS, Richmond W, Fu PC (1974) Enzymatic determination of total serum cholesterol. Clin Chem 20:470-475

Austin MA, Hokanson JE, Edwards KL (1998) Hypertriglyceridemia as a cardiovascular risk factor. Am J Cardiol 81:7B-12B

Ballor DL, Keesey RE (1991) A meta-analysis of the factors affecting exercise-induced changes in body mass, fat mass and fat-free mass in males and females. Int J Obes 15:717-726

Bansal S, Buring JE, Rifai N, Mora S, Sacks FM, Ridker PM (2007) Fasting compared with nonfasting triglycerides and risk of cardiovascular events in women. JAMA 298:309-316

Carter SL, Rennie C, Tarnopolsky MA (2001) Substrate utilization during endurance exercise in men and women after endurance training. Am J Physiol Endocrinol Metab 280:E898-E907

Després JP, Tremblay B, Moorjani S, Lupien PJ, Thériault G, Nadeau A, Bouchard C (1990) Long-term exercise training with constant energy intake. 3: effects on plasma lipoprotein levels. Int J Obes 14:85-94

Després JP, Gagnon J, Bergeron J, Couillard C, Leon AS, Rao DC, Skinner JS, Wilmore JH, Bouchard C (1999) Plasma postheparin lipase activities in the HERITAGE Family Study: the reproducibility, gender differences, and associations with lipoprotein levels. HEalth, RIsk factors, exercise Training and GEnetics. Clin Biochem 32:157-165 
Devries MC, Hamadeh MJ, Phillips SM, Tarnopolsky MA (2006) Menstrual cycle phase and sex influence muscle glycogen utilization and glucose turnover during moderate-intensity endurance exercise. Am J Physiol Regul Integr Comp Physiol 291:R1120-R1128

Devries MC, Lowther SA, Glover AW, Hamadeh MJ, Tarnopolsky MA (2007) IMCL area density, but not IMCL utilization, is higher in women during moderate-intensity endurance exercise, compared with men. Am J Physiol Regul Integr Comp Physiol 293:R2336-R2342

Donnelly JE, Smith BK (2005) Is exercise effective for weight loss with ad libitum diet? Energy balance, compensation, and gender differences. Exerc Sport Sci Rev 33:169-174

Frayn KN (1983) Calculation of substrate oxidation rates in vivo from gaseous exchange. J Appl Physiol 55:628-634

Freedman DS, Jacobsen SJ, Barboriak JJ, Sobocinski KA, Anderson AJ, Kissebah AH, Sasse EA, Gruchow HW (1990) Body fat distribution and male/female differences in lipids and lipoproteins. Circulation 81:1498-1506

Friedewald WT, Levy RI, Fredrickson DS (1972) Estimation of the concentration of low-density lipoprotein cholesterol in plasma, without use of the preparative ultracentrifuge. Clin Chem 18:499-502

Friedlander AL, Casazza GA, Horning MA, Budinger TF, Brooks GA (1998) Effects of exercise intensity and training on lipid metabolism in young women. Am J Physiol Endocrinol Metab 275:E853-E863

Friedlander AL, Casazza GA, Horning MA, Usaj A, Brooks GA (1999) Endurance training increases fatty acid turnover, but not fat oxidation, in young men. J Appl Physiol 86:2097-2105

Gill JM, Herd SL, Vora V, Hardman AE (2003) Effects of a brisk walk on lipoprotein lipase activity and plasma triglyceride concentrations in the fasted and postprandial states. Eur J Appl Physiol 89:184-190

Gordon PM, Visich PS, Goss FL, Fowler S, Warty V, Denys BJ, Metz KF, Robertson J (1996) Comparison of exercise and normal variability on HDL cholesterol concentrations and lipolytic activity. Int J Sports Med 17:332-337

Henderson GC, Fattor JA, Horning MA, Faghihnia N, Johnson ML, Mau TL, Luke-Zeitoun M, Brooks GA (2007a) Lipolysis and fatty acid metabolism in men and women during the postexercise recovery period. J Physiol 584:963-981

Henderson GC, Fattor JA, Horning MA, Faghihnia N, Luke-Zeitoun M, Brooks GA (2007b) Retention of intravenously infused $\left[{ }^{13} \mathrm{C}\right]$ bicarbonate is transiently increased during recovery from hard exercise. J Appl Physiol 103:1604-1612

Henderson GC, Fattor JA, Horning MA, Faghihnia N, Johnson ML, Luke-Zeitoun M, Brooks GA (2008) Glucoregulation is more precise in women than in men during postexercise recovery. Am J Clin Nutr 87:1686-1694

Horning MA, Friedlander AL, Casazza GA, Huie MJ, Brooks GA (1998) Arterial and 'arterialized' sampling sites do not change isotopic enrichment using [6, 6-D-glucose] and [1, 1, 2, 3, 3,-D-glycerol]. FASEB J 12:A854

Horton TJ, Pagliassotti MJ, Hobbs K, Hill JO (1998) Fuel metabolism in men and women during and after long-duration exercise. J Appl Physiol 85:1823-1832

Institutes of Medicine (2002) Dietary reference intakes for energy, carbohydrate, fiber, fat, fatty acids, cholesterol, protein, and amino acids. National Academies Press, Washington, DC

Jackson AS, Pollock ML (1978) Generalized equations for predicting body density of men. Br J Nutr 40:497-504

Jackson AS, Pollock ML, Ward A (1980) Generalized equations for predicting body density of women. Med Sci Sports Exerc $12: 175-181$
Johnson JL, Slentz CA, Duscha BD, Samsa GP, McCartney JS, Houmard JA, Kraus WE (2004) Gender and racial differences in lipoprotein subclass distributions: the STRRIDE study. Atherosclerosis 176:371-377

Katzmarzyk PT, Leon AS, Rankinen T, Gagnon J, Skinner JS, Wilmore JH, Rao DC, Bouchard C (2001) Changes in blood lipids consequent to aerobic exercise training related to changes in body fatness and aerobic fitness. Metabolism 50:841-848

Kiens B, Jorgensen I, Lewis S, Jensen G, Lithell H, Vessby B, Hoe S, Schnohr P (1980) Increased plasma HDL-cholesterol and apo A-1 in sedentary middle-aged men after physical conditioning. Eur J Clin Invest 10:203-209

Knuth ND, Horowitz JF (2006) The elevation of ingested lipids within plasma chylomicrons is prolonged in men compared with women. J Nutr 136:1498-1503

Kraus WE, Houmard JA, Duscha BD, Knetzger KJ, Wharton MB, McCartney JS, Bales CW, Henes S, Samsa GP, Otvos JD, Kulkarni KR, Slentz CA (2002) Effects of the amount and intensity of exercise on plasma lipoproteins. N Engl J Med 347:1483-1492

Lee R, Nieman D, Raval R, Blankenship J, Lee J (1991) The effects of acute moderate exercise on serum lipids and lipoproteins in mildly obese women. Int J Sports Med 12:537-542

Leon AS, Rice T, Mandel S, Després JP, Bergeron J, Gagnon J, Rao DC, Skinner JS, Wilmore JH, Bouchard C (2000) Blood lipid response to 20 weeks of supervised exercise in a large biracial population: the HERITAGE Family Study. Metabolism 49:513-520

Lewis GF, Uffelman KD, Szeto LW, Weller B, Steiner G (1995) Interaction between free fatty acids and insulin in the acute control of very low density lipoprotein production in humans. J Clin Invest 95:158-166

Magkos F, Wright DC, Patterson BW, Mohammed BS, Mittendorfer B (2006) Lipid metabolism response to a single, prolonged bout of endurance exercise in healthy young men. Am J Physiol Endocrinol Metab 290:E355-E362

Magkos F, Patterson BW, Mohammed BS, Mittendorfer B (2007) A single 1-h bout of evening exercise increases basal FFA flux without affecting VLDL-triglyceride and VLDL-apolipoprotein B-100 kinetics in untrained lean men. Am J Physiol Endocrinol Metab 292:E1568-E1574

Magkos F, Patterson BW, Mohammed BS, Mittendorfer B (2009) Basal adipose tissue and hepatic lipid kinetics are not affected by a single exercise bout of moderate duration and intensity in sedentary women. Clin Sci (Lond) 116:327-334

Nagele U, Hagele EO, Sauer G, Wiedemann E, Lehmann P, Wahlefeld AW, Gruber W (1984) Reagent for the enzymatic determination of serum total triglycerides with improved lipolytic efficiency. J Clin Chem Clin Biochem 22:165-174

Nichols AV, Krauss RM, Musliner TA (1986) Nondenaturing polyacrylamide gradient gel electrophoresis. Methods Enzymol 128:417-431

Phillips SM, Atkinson SA, Tarnopolsky MA, MacDougall JD (1993) Gender differences in leucine kinetics and nitrogen balance in endurance athletes. J Appl Physiol 75:2134-2141

Rifai N, King ME (1986) Immunoturbidimetric assays of apolipoproteins A, AI, AII, and B in serum. Clin Chem 32:957-961

Seip RL, Mair K, Cole TG, Semenkovich CF (1997) Induction of human skeletal muscle lipoprotein lipase gene expression by short-term exercise is transient. Am J Physiol Endocrinol Metab 272:E255-E261

Slentz CA, Houmard JA, Johnson JL, Bateman LA, Tanner CJ, McCartney JS, Duscha BD, Kraus WE (2007) Inactivity, exercise training and detraining, and plasma lipoproteins. STRRIDE: a randomized, controlled study of exercise intensity and amount. J Appl Physiol 103:432-442 
Smith SJ, Cooper GR, Henderson LO, Hannon WH (1987) An international collaborative study on standardization of apolipoproteins A-I and B. Part I. Evaluation of a lyophilized candidate reference and calibration material. Clin Chem 33:2240-2249

St-Amand J, Després JP, Lemieux S, Lamarche B, Moorjani S, Prud'homme D, Bouchard C, Lupien PJ (1995) Does lipoprotein or hepatic lipase activity explain the protective lipoprotein profile of premenopausal women? Metabolism 44:491-498

Stampfer MJ, Krauss RM, Ma J, Blanche PJ, Holl LG, Sacks FM, Hennekens CH (1996) A prospective study of triglyceride level, low-density lipoprotein particle diameter, and risk of myocardial infarction. JAMA 276:882-888

Tarnopolsky LJ, MacDougall JD, Atkinson SA, Tarnopolsky MA, Sutton JR (1990) Gender differences in substrate for endurance exercise. J Appl Physiol 68:302-308

Tarnopolsky MA, Rennie CD, Robertshaw HA, Fedak-Tarnopolsky SN, Devries MC, Hamadeh MJ (2007) Influence of endurance exercise training and sex on intramyocellular lipid and mitochondrial ultrastructure, substrate use, and mitochondrial enzyme activity. Am J Physiol Regul Integr Comp Physiol 292:R1271R1278

Thompson PD, Cullinane EM, Sady SP, Flynn MM, Bernier DN, Kantor MA, Saritelli AL, Herbert PN (1988) Modest changes in high-density lipoprotein concentration and metabolism with prolonged exercise training. Circulation 78:25-34

van Beaumont W (1973) Red cell volume with changes in plasma osmolarity during maximal exercise. J Appl Physiol 35:47-50

Warnick GR, Nguyen T, Albers AA (1985) Comparison of improved precipitation methods for quantification of high-density lipoprotein cholesterol. Clin Chem 31:217-222

Williams PT, Blanche PJ, Krauss RM (2005) Behavioral versus genetic correlates of lipoproteins and adiposity in identical twins discordant for exercise. Circulation 112:350-356 